\title{
PRODUTIVIDADE DE SOJA EM SEMEADURA DIRETA INFLUENCIADA POR PROFUNDIDADE DO SULCADOR DE ADUBO E DOSES DE RESÍDUO EM SISTEMA IRRIGADO E NÃO IRRIGADO ${ }^{1}$
}

\author{
RICARDO L. DA S. HERZOG ${ }^{2}$, RENATO LEVIEN ${ }^{3}$, CARLOS R. TREIN ${ }^{3}$
}

\begin{abstract}
RESUMO: O experimento foi conduzido na EEA-UFRGS, em Argissolo Vermelho distrófico típico, com o objetivo de quantificar o volume de solo mobilizado e a produção total de biomassa de soja em uma área de campo nativo, anteriormente cultivada com aveia-preta. Após a colheita, o resíduo de aveia foi distribuído nas parcelas, nas doses de $0 ; 2 ; 3 ; 4 ; 5$ e $6 \mathrm{Mg} \mathrm{ha}^{-1}$, que constituíram os tratamentos principais, os quais, por sua vez, foram subdivididos em função de profundidades $(0,06 \mathrm{~m}$ e $0,12 \mathrm{~m}$ ) de atuação dos sulcadores de adubo, tipo facão, da semeadora-adubadora. $\mathrm{O}$ delineamento foi o de blocos casualizados, com três repetições. Os tratamentos foram conduzidos em áreas distintas, com e sem irrigação. O volume de solo mobilizado pelos sulcadores de adubo foi $53 \%$ maior a $0,12 \mathrm{~m}$ do que a $0,06 \mathrm{~m}$, não havendo diferença em função da dose de resíduo de aveia. A produtividade de grãos, massa seca da parte aérea e de raízes, na profundidade de 0 a $0,15 \mathrm{~m}$, não foi influenciada pela profundidade do sulcador e pela quantidade de resíduo de aveia-preta. Na média dos tratamentos, a irrigação suplementar aumentou em $11 \%$ a produtividade de grãos e a biomassa total da soja. Mesmo sem irrigação, a produtividade da soja foi superior à média do Rio Grande do Sul, confirmando seu potencial para implantação sobre o campo nativo, sem nenhum tipo de preparo de solo prévio.
\end{abstract}

PALAVRAS-CHAVE: biomassa, mobilização do solo, plantio direto.

\section{SOYBEANS PRODUCTIVITY IN DIRECT TILLAGE AFFECTED BY THE DEPTH OF FERTILIZER FURROW OPENER AND AMOUNT OF CROP RESIDUE, WITH AND WITHOUT IRRIGATION}

SUMMARY: To evaluate soybeans productivity on natural pasture fields, grown once with oats to produce grain and straw for soil cover, an experiment was carried out on a Typic Paleudult Soil at the Agricultural Experimental Station of the UFRGS, Eldorado do Sul - RS, Brazil. After mechanically harvesting oats, the straw was returned to plots in amounts of $0 ; 2 ; 3 ; 4 ; 5$ and $6 \mathrm{Mg} \mathrm{ha}^{-1}$; these were the main treatments, which, were divided according to the furrow opening depth $(0.06 \mathrm{~m}$ and $0.12 \mathrm{~m})$ by the shanks of the drill. The experimental design followed a random design, with three repetitions. The area was divided in two, with and without irrigation. The volume of soil mobilized by the fertilizer furrow openers was $53 \%$ higher when the working depth reached $0.12 \mathrm{~m}$ compared to $0.06 \mathrm{~m}$, but no difference due the amount of cover crop residues was attained. Grain yield, crop biomass and root mass to $0.15 \mathrm{~cm}$ depth did not differ with both soil working depth and crop residue cover. Irrigation increased in $11 \%$ grain yield and total biomass of soybeans. Even without irrigation, soybean productivity was higher than the Rio Grande do Sul State average, showing its suitability to be grown on native pastures under the no-till system.

KEYWORDS: vegetal biomass, soil disturbance, no-till.

\footnotetext{
${ }^{1}$ Extraído da dissertação apresentada pelo primeiro autor ao PPGCS-UFRGS para obtenção do título de Mestre em Solos, área de Concentração Mecanização Agrícola. Apoio financeiro: CNPq-PRONEX-SOLOS.

${ }^{2}$ Eng ${ }^{\circ}$ Agrônomo, Mestre em Ciência do Solo, Empresa RiceTec Ltda., Rua São Paulo, 877, Porto Alegre - RS, Fone: (0XX51) 3346.9425, e-mail: rherzog@ ricetec.com.br.

${ }^{3}$ Eng $^{\mathrm{o}}$ Agrônomo, Professor Adjunto do Departamento de Solos, FA-UFRGS, Porto Alegre - RS.

Recebido pelo Conselho Editorial em: 27-5-2003

Aprovado pelo Conselho Editorial em: 18-10-2004
} 


\section{INTRODUÇÃO}

Nos tempos atuais, questionamentos sobre o melhor método de implantação do sistema de semeadura direta são freqüentes, principalmente quanto ao sulco produzido pela semeadora-adubadora, em relação à profundidade e área de solo mobilizada (CEPIK et al., 2002a). Estudos também vêm sendo realizados para determinar a melhor forma de disposição de fertilizantes no sistema de semeadura direta (KLEPKER \& ANGHINONI, 1995), tais como, a lanço, ao lado ou na linha de semeadura e, nesse caso, em que profundidade.

A semeadura direta é uma prática conservacionista especialmente adequada para condições de ambiente de regiões tropicais ou subtropicais, em que é necessário manter o solo protegido do Sol e da chuva (SÉGUY et al., 1996), substituindo processos mecânicos de preparo do solo por biológicos. A matéria orgânica sobre a superfície e o não-revolvimento do solo em toda extensão e profundidade propiciam condições para que a micro e mesovida presentes possam atuar, resultando em um solo estruturado, pronto para ser semeado (LAL, 1991).

A utilização da semeadura direta implica a conservação de resíduos na superfície do solo, o que garante a esse proteção contra o impacto direto da gota da chuva, reduzindo os riscos de perda de solo por erosão hídrica e auxiliando no controle de plantas daninhas (ROMAN \& VELLOSO, 1993).

No entanto, ainda é incerta a massa ideal de resíduos necessária para a cobertura do solo, que não afete a germinação e o desenvolvimento da cultura implantada nem o desempenho do conjunto trator semeadora-adubadora, devido a embuchamentos nos órgãos sulcadores e patinagem do trator. A patinagem também é afetada pelo tipo de sulcadores que equipam as semeadoras-adubadoras de precisão. Sulcadores que promovem maior mobilização do solo, como o caso dos facões, demandam maior esforço de tração e, conseqüentemente, podem induzir maior patinagem do trator, comparativamente aos de discos (CEPIK et al., 2002b).

O desenvolvimento radicular das culturas também pode ser afetado em solos mais compactados, como os sob semeadura direta em campo nativo submetido a pastejo direto por bovinos (TREIN et al., 1991). BARBER (1971) verificou que os preparos de solo influem na profundidade em que se localiza a densidade máxima das raízes. No preparo convencional, a máxima densidade de raízes foi encontrada entre 0,10 e $0,30 \mathrm{~m}$ de profundidade, enquanto, na semeadura direta, entre 0 e $0,10 \mathrm{~m}$. Maior mobilização do solo na linha de semeadura poderá ser uma alternativa para melhor distribuição do sistema radicular das culturas. Resultados semelhantes foram observados por ADEOYE (1982) na cultura do milho.

A disponibilidade hídrica durante a estação de crescimento da cultura da soja é a principal variável meteorológica determinante de oscilações da produtividade de grãos, mesmo em semeadura direta (CUNHA et al., 1999). No entanto, RODRIGUES et al. (2001) recomendam que a irrigação na cultura da soja deve ser realizada somente quando ocorrer deficiência hídrica elevada, pois, nesse caso, poderá ocasionar redução na produtividade de grãos; caso contrário, essa é excessivamente onerosa. No estudo conduzido por PEIXOTO et al. (2002), a deficiência hídrica ocorrida no período do enchimento de grãos da cultura da soja foi o que mais influenciou, negativamente, sua produção de massa seca da parte aérea, área foliar e produtividade de grãos.

O objetivo do presente trabalho foi avaliar o volume de solo mobilizado e a biomassa total (grãos, massa seca da parte aérea e de raízes até a profundidade de $0,15 \mathrm{~m}$ ) produzida pela cultura da soja, em semeadura direta sobre campo nativo anteriormente cultivado somente com aveia-preta, em função de doses de resíduo de aveia sobre a superfície e profundidades de atuação do sulcador do tipo facão da semeadora-adubadora de precisão, em áreas com e sem irrigação. 


\section{MATERIAL E MÉTODOS}

O experimento foi instalado e conduzido na Estação Experimental Agronômica da Universidade Federal do Rio Grande do Sul, localizada no município de Eldorado do Sul - RS, região fisiográfica da Depressão Central. O solo é um Argissolo Vermelho distrófico típico - PVd (EMBRAPA, 1999), com $511 ; 163$ e $326 \mathrm{~g} \mathrm{~kg}^{-1}$ de areia, silte e argila, respectivamente. A região possui precipitação média anual de $1.440 \mathrm{~mm}$ e o clima, segundo classificação de Köeppen, é do tipo Cfa - subtropical de verão úmido quente (BERGAMASCHI \& GUADAGNIN, 1990).

O local onde o experimento foi instalado, possui declividade de 0,02 a $0,03 \mathrm{~m} \mathrm{~m}^{-1}$ e estava sem uso agrícola ou experimental há mais de 15 anos. A vegetação do campo nativo predominante na área era de plantas nativas típicas da região.

Para anteceder a cultura da soja, foi implantada a de aveia-preta (Avena strigosa Schreb) diretamente sobre o campo nativo dessecado quimicamente, após a aplicação, a lanço, de $2 \mathrm{Mg} \mathrm{ha}^{-1}$ de calcário dolomítico, PRNT 67\%. A escolha deveu-se ao fato de ser uma gramínea anual rústica, com grande capacidade de perfilhamento, tolerante à seca e pouco exigente em fertilidade e que pode alcançar uma produção de matéria seca de até $6 \mathrm{Mg} \mathrm{ha}^{-1}$.

A cultura da aveia-preta foi conduzida de forma a atender às necessidades do delineamento experimental, ou seja, doses de palha de $0 ; 2 ; 3 ; 4 ; 5$ e $6 \mathrm{Mg} \mathrm{ha}^{-1}$ na época da semeadura da soja. A aveia foi semeada com semeadora-adubadora de fluxo contínuo, com 11 linhas espaçadas de 0,20 m e na profundidade de $0,03 \mathrm{~m}$. Todas as parcelas foram semeadas com aveia, mas, logo após a emergência, aquelas sorteadas com $0 \mathrm{Mg} \mathrm{ha}^{-1}$ de resíduo foram dessecadas com herbicida de ação total. Na época de aplicação da adubação de cobertura, nas parcelas em que se pretendia produção de 2 e $3 \mathrm{Mg} \mathrm{ha}^{-1}$ de massa seca da parte aérea da aveia, foram aplicados $60 \mathrm{~kg} \mathrm{ha}^{-1}$ de nitrogênio e, nas demais, $110 \mathrm{~kg} \mathrm{ha}^{-1}$.

Após a aveia atingir o ponto de maturação, foi efetuada sua colheita mecânica, com colhedora de grãos da marca SLC-John Deere, modelo 1165. Durante a colheita, a palha proveniente do saca-palhas e das peneiras da colhedora foi coletada em lona plástica para ser posteriormente distribuída nas parcelas em seis doses $\left(0 ; 2 ; 3 ; 4 ; 5\right.$ e $\left.6 \mathrm{Mg} \mathrm{ha}^{-1}\right)$, que constituíram os tratamentos principais $(7 \mathrm{~m} \mathrm{x} 5$

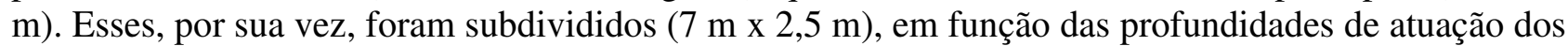
sulcadores de adubo $(0,06$ e $0,12 \mathrm{~m})$ da semeadora-adubadora e que constituíram os tratamentos secundários. Foi utilizado o delineamento de blocos casualizados, com três repetições. O experimento foi implantado em duas áreas contíguas, com o mesmo tipo de solo e de declividade do terreno onde, em uma delas, foi empregada, sempre que necessário, irrigação suplementar quando o teor de água fosse inferior à capacidade de campo. O sistema de irrigação utilizado foi o de aspersão, com taxa média de aplicação de $10 \mathrm{~mm} \mathrm{~h}^{-1}$. Durante o ciclo da soja, ou seja, de novembro a abril, as precipitações mensais foram de $163 ; 92 ; 127 ; 75 ; 143$ e $122 \mathrm{~mm}$, respectivamente. Foram efetuadas irrigações em dezembro, janeiro, fevereiro e março, com aplicação de 42; 40; 53 e $24 \mathrm{~mm}$ de água, respectivamente.

A cultura da soja foi semeada com semeadora-adubadora de precisão de cinco linhas, montada, marca Vence-Tudo, modelo 11500 , com espaçamento de $0,45 \mathrm{~m}$ entre as linhas, tracionada por trator da marca John Deere, modelo 5600, com tração dianteira auxiliar (TDA), potência máxima de $53 \mathrm{~kW}$ $(72 \mathrm{cv})$ no motor, massa de $3.520 \mathrm{~kg}$, pneus traseiros 18.4-30R1, dianteiros 12.4-24R1, inflados à pressão de 95 e $110 \mathrm{kPa}$, respectivamente. A máquina estava dotada de sistema de abertura do sulco e de semeadura composto por disco de corte de resteva liso de 0,356 m (14") de diâmetro, sulcadores de adubo do tipo facão, com ponteiras de $0,025 \mathrm{~m}$ de largura e ângulo de ataque de $20^{\circ}$, sulcadores para semente tipo discos duplos com 0,330 m (13") e rodas compactadoras dispostas em "V" com 0,305 m (12") de diâmetro. Os dosadores de adubo foram do tipo rotor dentado horizontal acionado por rosca sem fim e os de sementes do tipo discos, horizontais perfurados. 
A semeadura da soja foi realizada na densidade de 300.000 sementes por hectare, variedade FEPAGRO RS10, com poder germinativo de 60\%. A adubação de manutenção constou de uma mistura de $200 \mathrm{~kg} \mathrm{ha}^{-1}$ de triplo superfosfato (0-42-0) mais $200 \mathrm{~kg} \mathrm{ha}^{-1}$ de cloreto de potássio (0-0-60).

A velocidade de semeadura foi de $5,2 \mathrm{~km} \mathrm{~h}^{-1}$ e o teor médio de água no solo (base gravimétrica), no dia em que a mesma foi efetuada, foi de $0,180 \mathrm{~kg} \mathrm{~kg}^{-1}$, na profundidade de 0 a $0,12 \mathrm{~m}$. A profundidade média de colocação das sementes foi de $0,05 \mathrm{~m}$, enquanto a aplicação do fertilizante mineral foi realizada em duas profundidades $(0,06$ e $0,12 \mathrm{~m})$. Para isso, modificou-se a profundidade de atuação do sulcador de adubo, com o objetivo de avaliar a área de solo mobilizado e sua influência na cultura da soja.

$\mathrm{Na}$ época da semeadura da soja, na profundidade de 0 a $0,20 \mathrm{~m}$, a densidade do solo era de $169 \mathrm{~kg} \mathrm{~m}^{-3}$ e sua resistência à penetração de $1,93 \mathrm{MPa}$, determinada com teor de água de $0,130 \mathrm{~kg} \mathrm{~kg}^{-1}$.

$\mathrm{O}$ volume de solo mobilizado por hectare $\left(\mathrm{m}^{3} \mathrm{ha}^{-1}\right)$ foi obtido pela multiplicação da área de seção transversal de solo mobilizada na linha de semeadura $\left(\mathrm{m}^{2}\right)$, pela distância total de sulcos $(\mathrm{m})$. A área de seção transversal de solo mobilizado foi avaliada com perfilômetro, com hastes espaçadas em $0,01 \mathrm{~m}$, realizando-se duas determinações em cada parcela.

A produtividade de grãos e de massa seca da parte aérea foi determinada na colheita da soja. Primeiramente, foram cortadas e pesadas todas as plantas presentes na área útil das parcelas $\left(17,5 \mathrm{~m}^{2}\right)$. Após a trilha do material, os grãos foram pesados e sua massa corrigida para 13\% de umidade.

A massa de raízes foi obtida por meio de coleta de amostras com trado calador, com $0,042 \mathrm{~m}$ de diâmetro, a $0,15 \mathrm{~m}$ de profundidade. As amostras foram coletadas na linha de semeadura e a $0,10 \mathrm{~m}$ para as laterais da mesma, tomando-se o cuidado de não tomar amostras em locais com presença de plantas invasoras. Após processamento para separação das raízes da massa de solo, as mesmas foram secas em estufa e pesadas.

\section{RESULTADOS E DISCUSSÃO}

O volume de solo mobilizado pelo sulcador de adubo da semeadora-adubadora (Tabela 1) foi maior na profundidade de $0,12 \mathrm{~m}$ do que na de $0,06 \mathrm{~m}$, com acréscimo, em média, de $52 \%$. Resultados semelhantes foram encontrados em trabalhos de MION et al. (2002) e OLIVEIRA (2000). Porém, não foi constatada diferença significativa em função da dose de resíduo de aveia-preta existente sobre o solo no momento da semeadura, nas duas profundidades de atuação do sulcador. Esses resultados indicam que a mobilização do solo efetuada pelo sulcador de adubo da semeadora-adubadora não foi influenciada pelo tipo de cobertura presente na superfície do solo (campo nativo, aveia-preta), nem pelas doses de resíduo.

TABELA 1. Volume de solo mobilizado $\left(\mathrm{m}^{3} \mathrm{ha}^{-1}\right)$ na operação de semeadura da soja para as duas profundidades do sulcador de adubo e doses de resíduo.

\begin{tabular}{clcc}
\hline Doses de Resíduo & \multicolumn{2}{c}{ Profundidade do Sulcador de Adubo } & \multirow{2}{*}{ Média ${ }^{(1)}$} \\
\cline { 2 - 3 } Mg ha $^{-1}$ & $0,06 \mathrm{~m}$ & $0,12 \mathrm{~m}$ & $91,2 \mathrm{a}$ \\
2 & 65,6 & 96,8 & $92,6 \mathrm{a}$ \\
3 & 67,0 & 118,6 & $92,4 \mathrm{a}$ \\
4 & 75,5 & 109,5 & $98,7 \mathrm{a}$ \\
5 & 78,4 & 119,1 & $89,6 \mathrm{a}$ \\
6 & 65,0 & 114,7 & $98,7 \mathrm{a}$ \\
\hline Média $^{(1)}$ & 87,3 & 110,1 & 92,2 \\
\hline
\end{tabular}

C.V. doses $=17,7 \% \quad$ C.V. profundidade $=19,9 \%$

(1) Médias seguidas de mesma letra minúscula nas colunas e maiúscula nas linhas não diferem entre si, pelo teste de Tukey, $(\mathrm{P}>0,05)$. 
A produtividade de grãos de soja (Tabelas 2 e 3) não apresentou diferenças significativas em função dos tratamentos doses de resíduo e profundidade do sulcador de adubo da semeadoraadubadora, mesmo com a aplicação de água via irrigação. Na média dos tratamentos em que se utilizou irrigação, houve incremento de $300 \mathrm{~kg} \mathrm{ha}^{-1}$ de grãos em relação às parcelas conduzidas somente com precipitação natural. Esses resultados estão de acordo com os obtidos por PEIXOTO et al. (2002), uma vez que, nesse experimento, também não houve deficiência hídrica pronunciada na fase mais crítica do desenvolvimento da cultura, ou seja, a de enchimento de grãos (fevereiro e março).

A implantação da cultura da soja, em semeadura direta sobre campo nativo, resultou em um apreciável rendimento de grãos, tanto com o uso da irrigação, como sem seu uso, ou seja, 3.334 e $2.996 \mathrm{~kg} \mathrm{ha}^{-1}$, respectivamente. Resultado semelhante foi obtido por NICOLOSO et al. (2002), que implantaram a cultura da soja diretamente sobre o campo nativo sem prévia correção da acidez do solo com calcário, chegando a uma produtividade de grãos de $3.500 \mathrm{~kg} \mathrm{ha}^{-1}$. MOREIRA et al. (2002), avaliando a produtividade de grãos de soja em Latossolo Vermelho distrófico típico, sob semeadura direta, cultivo mínimo e preparo convencional, não encontraram diferenças significativas entre os mesmos, com valores de $3.207 ; 3.214$ e $3.094 \mathrm{~kg} \mathrm{ha}^{-1}$, respectivamente.

TABELA 2. Produtividade de grãos de soja $\left(\mathrm{kg} \mathrm{ha}^{-1}\right)$, com irrigação, para as duas profundidades do sulcador de adubo e doses de resíduo.

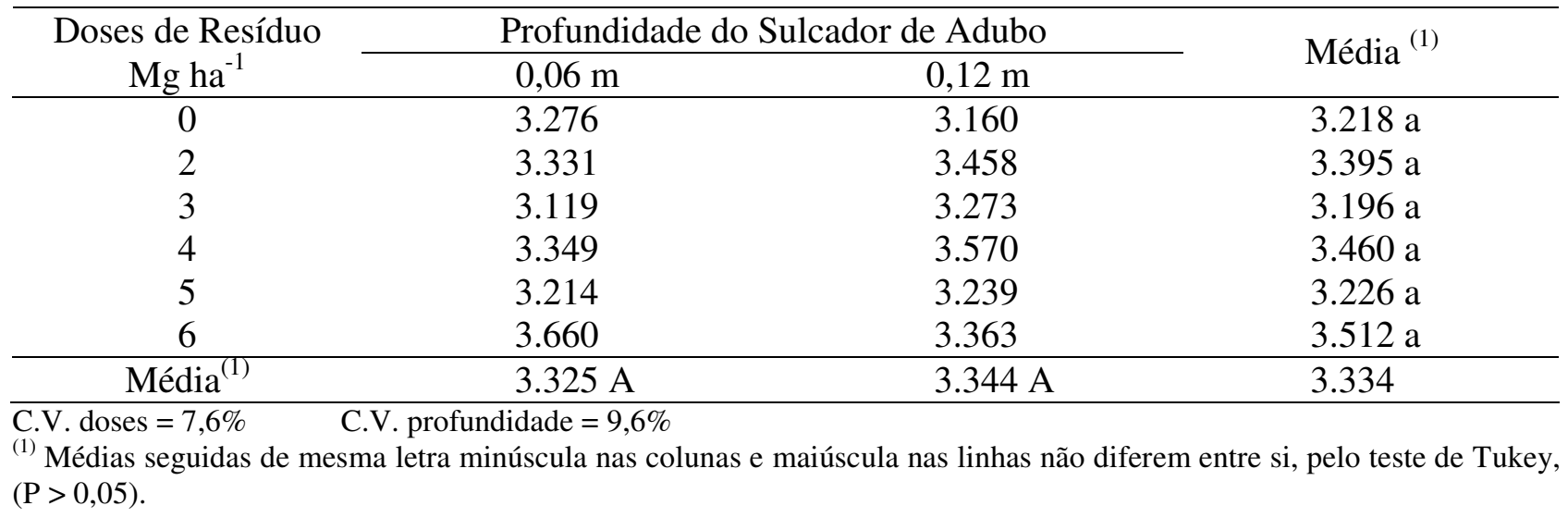

TABELA 3. Produtividade de grãos de soja $\left(\mathrm{kg} \mathrm{ha}^{-1}\right)$, sem irrigação, para as duas profundidades do sulcador de adubo e doses de resíduo.

\begin{tabular}{cccc}
\hline \multirow{2}{*}{$\begin{array}{c}\text { Doses de Resíduo } \\
\text { Mg ha }^{-1}\end{array}$} & \multicolumn{2}{c}{ Profundidade do Sulcador de Adubo } & \multirow{2}{*}{ Média $^{(1)}$} \\
\cline { 2 - 3 } & $0,06 \mathrm{~m}$ & $0,12 \mathrm{~m}$ & $2.837 \mathrm{a}$ \\
2 & 2.714 & 2.961 & $3.025 \mathrm{a}$ \\
3 & 2.995 & 3.055 & $2.951 \mathrm{a}$ \\
4 & 2.944 & 2.957 & $3.065 \mathrm{a}$ \\
5 & 2.942 & 3.187 & $2.963 \mathrm{a}$ \\
6 & 2.910 & 3.015 & $3.134 \mathrm{a}$ \\
\hline Média $^{(1)}$ & 3.158 & 3.109 & 2.996 \\
\hline
\end{tabular}

C.V. doses $=8,2 \% \quad$ C.V. profundidade $=6,5 \%$

${ }^{(1)}$ Médias seguidas de mesma letra minúscula nas colunas e maiúscula nas linhas não diferem entre si, pelo teste de Tukey, $(\mathrm{P}>0,05)$.

A massa seca da parte aérea da cultura da soja (Tabelas 4 e 5), a exemplo da produtividade de grãos, também não foi influenciada pelos tratamentos e foi, praticamente, igual entre o experimento 
que recebeu e não recebeu irrigação suplementar. NICOLOSO et al. (2002), em semeadura direta de soja sobre campo nativo em Argissolo Vermelho-Amarelo, sem prévia correção da acidez do solo, chegaram ao resultado de $2.223 \mathrm{~kg} \mathrm{ha}^{-1}$ de massa seca da parte aérea.

TABELA 4. Produção de massa seca da parte aérea de soja $\left(\mathrm{kg} \mathrm{ha}^{-1}\right)$, com o uso de irrigação para as duas profundidades do sulcador de adubo e doses de resíduo.

\begin{tabular}{cccc}
\hline Doses de Resíduo & \multicolumn{2}{c}{ Profundidade do Sulcador de Adubo } & \multirow{2}{*}{ Média $^{(1)}$} \\
\cline { 2 - 3 } $\mathrm{Mg} \mathrm{ha}^{-1}$ & $0,06 \mathrm{~m}$ & $0,12 \mathrm{~m}$ & $2.246 \mathrm{a}$ \\
2 & 2.331 & 2.160 & $2.362 \mathrm{a}$ \\
3 & 2.447 & 2.453 & $2.521 \mathrm{a}$ \\
4 & 2.101 & 2.618 & $2.298 \mathrm{a}$ \\
5 & 2.432 & 2.218 & $2.319 \mathrm{a}$ \\
6 & 2.217 & 2.420 & $2.346 \mathrm{a}$ \\
\hline Média $^{(1)}$ & 2.377 & 2.315 & 2.348 \\
\hline
\end{tabular}

C.V. doses $=18,5 \% \quad$ C.V. profundidade $=12,2 \%$

${ }^{(1)}$ Médias seguidas de mesma letra minúscula nas colunas e maiúscula nas linhas não diferem entre si, pelo teste de Tukey, $(\mathrm{P}>0,05)$.

TABELA 5. Produção de massa seca da parte aérea de soja $\left(\mathrm{kg} \mathrm{ha}^{-1}\right)$, sem o uso de irrigação para as duas profundidades do sulcador de adubo e doses de resíduo.

\begin{tabular}{cccc}
\hline $\begin{array}{c}\text { Doses de Resíduo } \\
\mathrm{Mg} \mathrm{ha}^{-1}\end{array}$ & \multicolumn{2}{c}{ Profundidade do Sulcador de Adubo } & \multirow{2}{*}{ Média $^{(1)}$} \\
\cline { 2 - 3 } & $0,06 \mathrm{~m}$ & $0,12 \mathrm{~m}$ & $2.355 \mathrm{a}$ \\
2 & 2.231 & 2.480 & $2.523 \mathrm{a}$ \\
3 & 2.507 & 2.539 & $2.307 \mathrm{a}$ \\
4 & 2.141 & 2.474 & $2.594 \mathrm{a}$ \\
5 & 2.613 & 2.574 & $2.371 \mathrm{a}$ \\
6 & 2.221 & 2.521 & $2.230 \mathrm{a}$ \\
\hline Média $^{(1)}$ & 2.163 & 2.297 & 2.397 \\
\hline
\end{tabular}

C.V. doses $=14,2 \% \quad$ C.V. profundidade $=17,8 \%$

(1) Médias seguidas de mesma letra minúscula nas colunas e maiúscula nas linhas não diferem entre si, pelo teste de Tukey, $(\mathrm{P}>0,05)$.

A massa de raízes da cultura da soja (Tabelas 6 e 7), coletada na época de colheita até a profundidade $0,15 \mathrm{~m}$ no solo, não diferiu entre as profundidades de atuação do sulcador, discordando de BARBER (1971) e ADEOYE (1982), que afirmam que é possível melhor enraizamento com maior mobilização do solo. Com irrigação (Tabela 6), não houve diferença entre os tratamentos de doses de resíduo na profundidade de $0,06 \mathrm{~m}$, porém, nos tratamentos com ausência de irrigação (Tabela 7), houve diferenças significativas, ou seja, baixas quantidades de resíduos propiciaram maior massa radicular. Quando o sulcador trabalhou a $0,12 \mathrm{~m}$, verificou-se o contrário, ou seja, houve diferença quando se usou irrigação, mantendo-se a mesma observação de maior produção de massa radicular nas menores doses de resíduos empregadas. Sem irrigação, a 0,12 m de profundidade do sulcador, não houve diferença entre as doses de resíduos. Várias hipóteses poderiam ser levantadas para tentar explicar os dados, entre elas, alelopatia ou retenção de apreciável quantidade de água (chuva e irrigação) causadas por elevadas doses de resíduo, precisão do método de avaliação empregado, variabilidade espacial. No entanto, apenas com os dados da pesquisa, não foi possível estabelecer uma relação entre causa e efeito entre essas variáveis, sendo necessários mais estudos em outras condições de solo e clima. 
Na média de todos os tratamentos, o uso de irrigação promoveu um acréscimo de $500 \mathrm{~kg} \mathrm{ha}^{-1}$ na massa de raízes até $0,15 \mathrm{~m}$ de profundidade. Isso pode explicar, em parte, a maior produtividade de grãos também obtida com uso da irrigação. ANGHINONI et al. (2002) encontraram uma distribuição de raízes no perfil do solo relacionada com a distribuição de fósforo e dependente do ano. Em 1990, verificaram que $42 \%$ da massa de raízes se encontrava na camada de 0 a $0,05 \mathrm{~m}$; em 2000, apenas $23 \%$. Os autores atribuíram o resultado à melhor distribuição de fósforo no perfil do solo, devido às mobilizações que o mesmo sofreu, mesmo em semeadura direta, nas safras anteriores (verão e inverno).

TABELA 6. Massa seca de raízes de soja no momento da colheita $\left(\mathrm{kg} \mathrm{ha}^{-1}\right)$, na profundidade de 0 a $0,15 \mathrm{~m}$, com irrigação, para as duas profundidades do sulcador de adubo e doses de resíduo.

\begin{tabular}{|c|c|c|c|}
\hline \multirow{2}{*}{$\begin{array}{c}\text { Doses de Resíduo } \\
\mathrm{Mg} \mathrm{ha}^{-1}\end{array}$} & \multicolumn{2}{|c|}{ Profundidade do Sulcador de Adubo } & \multirow{2}{*}{ Média } \\
\hline & $0,06 \mathrm{~m}^{(1)}$ & $0,12 \mathrm{~m}^{(1)}$ & \\
\hline 0 & $3.516 \mathrm{a}$ & $3.545 \mathrm{a}$ & 3.530 \\
\hline 2 & $3.641 \mathrm{a}$ & $3.296 \mathrm{a}$ & 3.469 \\
\hline 3 & $3.200 \mathrm{a}$ & $3.064 \mathrm{ab}$ & 3.132 \\
\hline 4 & $3.296 \mathrm{a}$ & $2.823 \mathrm{ab}$ & 3.060 \\
\hline 5 & $2.863 \mathrm{a}$ & $2.807 \mathrm{ab}$ & 2.835 \\
\hline 6 & $2.807 \mathrm{a}$ & $2.230 \mathrm{~b}$ & 2.518 \\
\hline Média $^{(1)}$ & $3.220 \mathrm{~A}$ & $2.961 \mathrm{~A}$ & 3.090 \\
\hline
\end{tabular}

TABELA 7. Massa seca de raízes de soja no momento da colheita $\left(\mathrm{kg} \mathrm{ha}^{-1}\right)$, na profundidade de 0 a $0,15 \mathrm{~m}$, sem irrigação, para as duas profundidades do sulcador de adubo e doses de resíduo.

\begin{tabular}{clcc}
\hline \multirow{2}{*}{$\begin{array}{c}\text { Doses de Resíduo } \\
\text { Mg ha }^{-1}\end{array}$} & \multicolumn{2}{c}{ Profundidade do Sulcador de Adubo } & \multirow{2}{*}{ Média } \\
\cline { 2 - 3 } & $0,06 \mathrm{~m}^{(1)}$ & $0,12 \mathrm{~m}^{(1)}$ & 3.084 \\
2 & $3.280 \mathrm{a}$ & $2.887 \mathrm{a}$ & 2.775 \\
3 & $2.839 \mathrm{ab}$ & $2.711 \mathrm{a}$ & 2.563 \\
4 & $2.928 \mathrm{ab}$ & $2.198 \mathrm{a}$ & 2.400 \\
5 & $2.206 \mathrm{~b}$ & $2.262 \mathrm{a}$ & 2.226 \\
6 & $2.254 \mathrm{ab}$ & $2.198 \mathrm{a}$ & 2.338 \\
\hline Média $^{(1)}$ & $2.430 \mathrm{ab}$ & $2.246 \mathrm{a}$ & 2.564 \\
\hline
\end{tabular}

C.V. doses $=15,1 \% \quad$ C.V. profundidade $=17,2 \%$

${ }^{(1)}$ Médias seguidas de mesma letra minúscula nas colunas e maiúscula nas linhas não diferem entre si, pelo teste de Tukey, $(\mathrm{P}>0,05)$.

Em relação à biomassa total da cultura da soja (grãos, parte aérea e de raízes até $0,15 \mathrm{~m}$ ), não foi observada diferença entre os tratamentos profundidade do sulcador de adubo e doses de resíduo, independentemente do uso de irrigação (Tabelas 8 e 9). Na média de todos os tratamentos, verificou-se uma diferença em torno de $1,0 \mathrm{Mg} \mathrm{ha}^{-1}$ de biomassa a favor das parcelas que receberam irrigação. 
TABELA 8. Produção total de resíduos de parte aérea, raízes na camada de $0-0,15 \mathrm{~m}$ de profundidade e de grãos $\left(\mathrm{kg} \mathrm{ha}^{-1}\right)$, com irrigação, para as duas profundidades do sulcador de adubo e doses de resíduo.

\begin{tabular}{cccc}
\hline Doses de Resíduo & \multicolumn{2}{c}{ Profundidade do Sulcador de Adubo } & \multirow{2}{*}{ Média $^{(1)}$} \\
\cline { 2 - 3 } Mg ha $^{-1}$ & $0,06 \mathrm{~m}$ & $0,12 \mathrm{~m}$ & $9.699 \mathrm{a}$ \\
2 & 10.333 & 9.066 & $9.275 \mathrm{a}$ \\
3 & 9.121 & 9.429 & $9.053 \mathrm{a}$ \\
4 & 8.942 & 9.164 & $9.039 \mathrm{a}$ \\
5 & 9.238 & 8.840 & $8.586 \mathrm{a}$ \\
6 & 8.499 & 8.673 & $8.599 \mathrm{a}$ \\
\hline Média $^{(1)}$ & 9.077 & 8.122 & 9.042 \\
\hline
\end{tabular}

C.V. doses $=9,5 \% \quad$ C.V. profundidade $=12,1 \%$

(1) Médias seguidas de mesma letra minúscula nas colunas e maiúscula nas linhas não diferem entre si, pelo teste de Tukey, $(\mathrm{P}>0,05)$.

TABELA 9. Produção total de resíduos de parte aérea, raízes na camada de 0-0,15 $\mathrm{m}$ de profundidade e de grãos $\left(\mathrm{kg} \mathrm{ha}^{-1}\right)$, sem irrigação, para as duas profundidades do sulcador de adubo e doses de resíduo.

\begin{tabular}{cccc}
\hline Doses de Resíduo & \multicolumn{2}{c}{ Profundidade do Sulcador de Adubo } & \multirow{2}{*}{ Média $^{(1)}$} \\
\cline { 2 - 3 } Mg ha $^{-1}$ & $0,06 \mathrm{~m}$ & $0,12 \mathrm{~m}$ & $8.458 \mathrm{a}$ \\
2 & 8.398 & 8.517 & $8.517 \mathrm{a}$ \\
3 & 8.533 & 8.500 & $8.009 \mathrm{a}$ \\
4 & 8.200 & 7.818 & $8.088 \mathrm{a}$ \\
5 & 7.949 & 8.226 & $7.748 \mathrm{a}$ \\
6 & 7.571 & 7.926 & $7.902 \mathrm{a}$ \\
\hline Média $^{(1)}$ & 7.953 & 7.851 & 8.120 \\
\hline
\end{tabular}

C.V. doses $=7,75 \% \quad$ C.V. profundidade $=9,07 \%$

(1) Médias seguidas de mesma letra minúscula nas colunas e maiúscula nas linhas não diferem entre si, pelo teste de Tukey, $(\mathrm{P}>0,05)$.

\section{CONCLUSÕES}

O volume de solo mobilizado pelos sulcadores de adubo foi $53 \%$ maior a $0,12 \mathrm{~m}$ do que a 0,06 m, não havendo diferença em função da dose de resíduo de aveia. A produtividade de grãos, massa da parte aérea e de raízes, na profundidade de 0 a $0,15 \mathrm{~m}$, não foi influenciada pela profundidade do sulcador e resíduo de aveia. Na média dos tratamentos, a irrigação suplementar aumentou em $11 \%$ a produtividade de grãos e a biomassa total da soja. Mesmo sem irrigação, a produtividade da soja foi superior à média do Rio Grande do Sul, confirmando seu potencial para implantação sobre o campo nativo, sem nenhum tipo de preparo de solo prévio.

\section{REFERÊNCIAS}

ADEOYE, K.B. Effect of tillage depth on physical properties of a tropical soil and on yield of maize, sorghum and cotton. Soil \& Tillage Research, Amsterdam, v.2, n.3, p.225-31, 1982.

ANGHINONI, I.; HENNIGEM, F.J.; TOMASI, C.A.; KLEPKER, D. Distribuição de fósforo e de raízes no perfil de um Argissolo em função do modo de aplicação do adubo fosfatado, sistemas de preparo e tempo de cultivo. In: REUNIẪO BRASILEIRA DE MANEJO E CONSERVAÇÃO DO 
SOLO E DA ÁGUA, 14., 2002, Cuiabá. Anais... Cuiabá: Sociedade Brasileira de Ciência do Solo, 2002. 1 CD ROM.

BARBER, S.A. Effect of tillage practice on corn (Zea mays L.) root distribution and morphology. Agronomy Journal, Madison, v.63, n.5, p.724-6, 1971.

BERGAMASCHI, H.; GUADAGNIN, M.R. Agroclima da Estação Experimental Agronômica. 1990. 91 f. Dissertação (Mestrado em Plantas Forrageiras e Agrometeorologia) - Faculdade de Agronomia, Universidade Federal do Rio Grande do Sul, Porto Alegre, 1990.

CEPIK, C.T.C.; TREIN, C.R.; LEVIEN, R.; BEUTLER, J.F. Relação entre força de tração na haste sulcadora de semeadora-adubadora e a área mobilizada em semeadura direta. In: CONGRESSO BRASILEIRO DE ENGENHARIA AGRÍCOLA, 31., 2002, Salvador. Anais... Salvador: Sociedade Brasileira de Engenharia Agrícola, 2002a. 1 CD ROM.

CEPIK, C.T.C.; TREIN, C.R.; LEVIEN, R.; HERZOG, R.L.S. Patinagem do trator e força de tração de haste sulcadora de semeadora-adubadora de precisão em função de teores de água no solo. In: CONGRESSO BRASILEIRO DE ENGENHARIA AGRÍCOLA, 31., 2002, Salvador. Anais... Salvador: Sociedade Brasileira de Engenharia Agrícola, 2002b. 1 CD ROM.

CUNHA, G.R. da; HAAS, J.C.; DALMAGO, G.A. Perda de rendimento potencial em soja no Rio Grande do Sul por deficiência hídrica. Revista Brasileira de Agrometeorologia, Santa Maria , v.4, n.1, p.111-9, 1999.

EMPRESA BRASILEIRA DE PESQUISA AGROPECÁRIA. Sistema brasileiro de classificação de solos. Rio de Janeiro: EMBRAPA Solos, 1999. 412 p.

KLEPKER, D.; ANGUINONI, I. Características físicas e químicas do solo afetadas por métodos de preparo e modos de adubação. Revista Brasileira de Ciência do Solo, Campinas, v.19, n. 3, p.395-401, 1995.

LAL, R. Tillage and agricultural sustainability. Soil \& Tillage Research, Amsterdam, v.20, n.1, p.13346, 1991.

MION, R.L.; NERY, M.S.; CARVALHO, W.P.A.; RUIZ, E.R; FAGGION, F.; GROSSI, C.H.; MARQUES, J.P.; MAHL, D.; SILVA, A.R.B.; BENEZ, S.H. Influência da profundidade de trabalho de uma haste de semeadora na força de tração e na área de solo mobilizada em plantio direto. In: CONGRESSO BRASILEIRO DE ENGENHARIA AGRÍCOLA, 31., 2002, Salvador. Anais... Salvador: Sociedade Brasileira de Engenharia Agrícola, 2002. 1 CD ROM.

MOREIRA, S.G.; PROCHNOW, L.I.; KIEHL, J. de C.; PAULETTI, V. Produtividade de soja e acúmulo de nutrientes em função de sistemas de preparo. In: REUNIÃO BRASILEIRA DE MANEJO E CONSERVAÇÃO DO SOLO E DA ÁGUA, 14., 2002, Cuiabá. Anais... Cuiabá: Sociedade Brasileira de Ciência do Solo, 2002. 1 CD ROM.

NICOLOSO, R. da S.; LOVATO, T.; SENHOR, T.C.; SATTLER, R.A. Produção de grãos e fitomassa no pleno florescimento das culturas da soja e do milho quando implantadas sob campo nativo sem prévia correção da acidez do solo. In: REUNIÃO BRASILEIRA DE MANEJO E CONSERVAÇÃO DO SOLO E DA ÁGUA, 14., 2002, Cuiabá. Anais... Cuiabá: Sociedade Brasileira de Ciência do Solo, 2002. 1 CD ROM.

OLIVEIRA, M.F.B. de; SIQUEIRA, R.; RALISCH, R.; ARAÚJO, A.G. de; CASÃO JÚNIOR, R. Mobilização do solo por hastes sulcadores de semeadoras-adubadoras de plantio direto. In: CONGRESSO BRASILEIRO DE ENGENHARIA AGRÍCOLA, 29., 2000. Fortaleza. Anais... Fortaleza: Sociedade Brasileira de Engenharia Agrícola, 2000. 1 CD ROM. 
PEIXOTO, C.P.; PEIXOTO, M.; FREITAS, S.P.; SANTOS, A.R.; SILVA, V. Matéria seca, área foliar e rendimento de grãos em cultivares de soja sob déficit hídrico em diferentes fases fenológicas. In: CONGRESSO BRASILEIRO DE ENGENHARIA AGRÍCOLA, 31., 2002, Salvador. Anais... Salvador: Sociedade Brasileira de Engenharia Agrícola, 2002. 1 CD ROM.

RODRIGUES, M.; CARLESSO, R.; KUNZ, J.H.; MELO, G.L.; MICHELON, C. Manejo da irrigação da cultura da soja. In: CONGRESSO BRASILEIRO DE ENGENHARIA AGRÍCOLA, 30., 2001, Foz do Iguaçu. Anais... Foz do Iguaçu: Sociedade Brasileira de Engenharia Agrícola, 2001. 1 CD ROM.

ROMAN, E.S.; VELLOSO, J.A.R.O. Controle cultural, coberturas mortas e alelopatia em sistemas conservacionistas. In: EMPRESA BRASILEIRA DE PESQUISA AGROPECUÁRIA. Centro Nacional de Pesquisa de Trigo. Plantio Direto no Brasil. Passo Fundo: Aldeia Norte, 1993. p.77-84.

SÉGUY, L.; BOUZINAC, S.; TRENTINI, A. Construção de uma agricultura sustentável, lucrativa e adaptada aos entraves pedoclimáticos das regiões tropicais úmidas. Informe Agronômico, Londrina, v.74, n.1, p.2-20, 1996.

TREIN, C.R.; COGO, N.P.; LEVIEN, R. Métodos de preparo do solo na cultura do milho e ressemeadura do trevo, na rotação aveia + trevo/milho, após pastejo intensivo. Revista Brasileira de Ciência do Solo, Campinas, v.15, n.1, p.105-11, 1991. 